\title{
Speculative memory, the planetary, and genre fiction
}

As Pieter Vermeulen has recently argued, the scales of literary criticism have shifted of late. After 9/11, scrutiny of the American novel has focused on its reterritorialising or deterritorialising tendencies: whether it registers or represents the extraterritorial reach of America economically, politically or culturally and, more to the point, the structuring and constitutive presence of the global in American life; or, whether its parochial or domesticating scope constructs conceptual Homelands by which literature can contribute to exceptionalist versions of national identity and to the idea that global history is something that happens elsewhere but which, on occasion, traumatically breaches American borders. ${ }^{1}$ The parameters of this critical scrutiny were of course a vital intervention in the trauma paradigm that was so pervasive in literary criticism, theory and practice in the decade following 9/11, both localising and globalising American experience. However, as Vermeulen points out, literary criticism has in the last few years seen another rescaling by which the parameters used to contextualise literary practice have been vastly expanded across time and space an expansion informed by the Humanities' reconceptualisation of the Anthropocene. A concept that began in the Earth Sciences but which has gained remarkable traction across disciplines in the last few years, the 'Anthropocene' describes the primacy of human agency in shaping the planet's chemistry, engendering complex transformative processes over which humanity's geophysical agency has little control. There are varying interpretations around the Anthropocene's inception date. The majority of the International Commission on Stratigraphy's Working Group on the Anthropocene voted in 2016 to identify 1950 as a so-called golden spike (a collection of corresponding physical

1 Pieter Vermeulen, 'Don DeLillo's Point Omega, the Anthropocene, and the Scales of Literature, Studia Neophilologica, 1.14 (2014), pp.2-12 
reference points in the Earth's strata, biosphere and atmosphere), created by the fall out of atomic warfare and testing and the great acceleration of oil production and consumption from thereon, and thereby the marker of a geological shift. However, there is still a critical mass of academic research in the Humanities that synchronises the Anthropocene with industrial capitalism and so points to the beginning of the industrial revolution: the late eighteenth-century's inauguration of the large-scale burning of fossil fuels and consequent atmospheric emissions of carbon dioxide, the cumulative effects of which make climate change the most pronounced Anthropocenic characteristic. Whether the beginnings of radical changes to the climate are the signature of a new geological epoch, or whether those changes augment and are inextricable from a later epochal shift, anthropogenic climatic change is still representative of the Anthropocene and legible in the geological record that is being left by humanity's geophysical agency.

For Kate Marshall what also becomes legible in the reading of this geological inscription are the 'two sides to the desires encoded in the conceptual apparatus of the Anthropocene': a seeming affirmation of the egocentric, anthropocentric view that humanity can shape the chemistry and geology of the planet; and the nonanthropocentric view of a future from which our planetary inscriptions can be read, after our extinction, by a post-human archaeologist (which we can only imagine in the meantime in our attempted adoption of a posthumanist perspective). The problem is that the latter collapses into the former, because our insistent fantasies of a readable future beyond ourselves from which our geohistory is legible is an insistence on species agency $[\ldots .$.$] a rampant if frustrated desire for ubiquitous$ consciousness'.2

2 Kate Marshall, 'What are the Novels of the Anthropocene? American Fiction in Geological Time', American Literary History, 27.3 (2015), p.525. 
The impulse to colonise future times and spaces in and by the literary imagination leads Marshall to adapt Ramón Saldivar's concept of 'speculative realism' for an analysis of fictions of the Anthropocene (an adaptation further inspired by Fredric Jameson's reorientation of historical fiction towards the future). ${ }^{3}$ Broadly speaking, Saldivar's exploration of the use of fantasy in ethnic-American fiction moves beyond the identification of magical realism's expressive potential in relation to the extreme realties of oppression. The conceptualisation of speculative realism is an understanding of the hybridity of metafiction, realism, fantasy, and genre fiction as expressive of the historical possibilities of cultural and transcultural community; the work of counter-memory and historical representation; and the formation of political subjectivity. This expression is through a hyperbolic imagination (and negotiation) of the realities of racialised state control, historical violence and the ideological fantasies that underpin a collective sense of nationalist identity. ${ }^{4}$ These speculations on thinking and being otherwise in scenarios of oppression and violence will always foreground their ideological mediations (as well as the navigation of their material historical contexts) in a literary mode that calls attention to itself as a remediation of the historicist work done by previous forms of realism. Put otherwise, the expressive potential of speculative realism lies in its foregrounding the mediation of mediation of extreme American realities, in other words in its selfreflexiveness as a genre.

As such, Marshall finds that this cultural apparatus of speculation lends itself to the future as much as to the present and the past, or more particularly to the (re)mediations of the future. Marshall's enquiry into the speculations of fiction that dramatise

\footnotetext{
3 Fredric Jameson, The Antinomies of Realism (London and New York: Verso, 2013), pp.303-13.

${ }^{4}$ Ramón Saldivar, 'Historical Fantasy, Speculative Realism, and Postrace Aesthetics in Contemporary American Fiction', American Literary History, 23.3 (2011), pp. 574-99.
} 
consciousness of what we would call the Anthropocene focuses on attempts in the literature's diegesis to imagine how humanity's geologic inscriptions might be read from the future. What interests Marshall here is the way in which these literary 'experiments in nonhuman viewpoints' are embedded 'within the most human of geological formations rather than in speculative alternative geologies'. ${ }^{5}$ Marshall is not so much interested in the literary imagination of alien worlds as a means of grounding perspectives beyond the human but rather in novels that explore the way in which the residue of humanity might be read from the future but through the material conditions of the production and reproduction of human life and the ideological discourses and cultural forms concomitant with that materiality. In other words, this literature does not other the Anthropocene or postAnthropocene.

In mapping the widening scales of recent literary criticism and theory, and its accommodation of future-oriented historical fiction, this essay argues that fictions of the Anthropocene might also be characterised as fictions of future or, what I call, speculative memory. While Marshall focuses on fiction in which characters imagine how they and the remnants of humanity might be read from some point in the future, fictions of the Anthropocene also stage near, middle and far futures in which the effects of the unfolding Anthropocene are more discernible if not catastrophically realised and, from that future, the cultural remembrance of how this catastrophe came to be. In other words, what is remembered is an aetiology of the conditions that are imagined in the future but which are unfolding in the present of this literature's production and consumption.

My concept of speculative memory differs from recent theoretical gestures in environmental studies towards thinking about the future

${ }^{5}$ Marshall, p.533. 
anterior - that which will have been - in relation to remembrance, such as Greg Garrard's:

If climate change had a grammatical tense, it would be the future perfect subjunctive. We're being asked to look forward in order to look back on ourselves today with a sense of shame and embarrassment that we didn't act sooner and more dramatically. This is a mode we see a lot in apocalyptic fictions. ${ }^{6}$

Implicit in this statement is the identification of the cultural assumption that affect can substitute for politics or social organization and that the affectiveness naturalizes its very constructedness (and ideological significance). (Indeed, climate change does not have a grammatical tense, its narrative representation does.) Claire Colebrook's version of the future anterior, 'proleptic' or 'preliminary mourning', has more in common with speculative memory, and its interest in mediation, in that it points to the constructedness of the future's past. The preliminary mourning of the (anticipated) extinction of humanity under the conditions of the Anthropocene is the mourning of the past prior to a 'fragile, drowned or lost world' and so of 'what once made us human'. However, as Colebrook points out, this would be the anticipatory retrospection of past ecological equilibrium, or 'benevolent' nature, that was never objectively present. In effect, preliminary mourning remembers past representations of the environment. Thinking about climate

${ }^{6}$ quoted in Sebastian Groes, 'Introduction to Part III: Ecologies of Memory', in (ed.), Memory in Twenty-First Century: New Critical Perspectives from the Arts, Humanities, and Sciences (Basingstoke and New York: Palgrave Macmillan, 2016), p.141; see also Greg Garrard, 'Climate Change and the Art of Memory', 'http://thememorynetwork.net/category/ecologies-of-memory/, accessed 16 Feb 2017. 
change more specifically, the climate has always been changing, belying the idea that some previous, static (and undamaged) version could be restored (at least to memory). ${ }^{7}$

So, while Marshall's adaptation of speculative realism demonstrates how the imagination of a future vantage point from which retrospection might take place is mediated by the material and ideological conditions of the world within and without the novel, and Colebrook identifies a process of mourning that is nostalgic, the fiction of speculative memory demonstrates the mediations of what is actually remembered from the future as well as the mediated vantage points of retrospection. Indeed it is the centrality of memory to this futural literary speculation that foregounds mediation: future memory's mediation of the past, and the cultural forms memory takes (from the self-reflexiveness of the genre itself to its digetic cultural landscape), and the socio-economic, political and ideological discourses authorising those forms within and without the novel. ${ }^{8}$ In this sense, the conceptualisation of literary speculative memory honours a debt to Saldivar's seminal formulation of speculative realism in terms of that literature's negotatiated interpellation, and as this essay will find, literary-critical debates over literature's abilities to represent the Anthropocene pivot around the extent of geology's cultural relevance and meaningfulness versus its alien spatial and temporal scales - the ways it is mediated as opposed to its unrepresentability. Furthermore, while speculative realism countenances scenarios of oppression, as the foregoing argues speculative memory navigates more chronic, enduring, forms of violence.

${ }^{7}$ Claire Colebrook, 'Time That Is Intolerant', in Sebastian Groes (ed.), 'Introduction to Part III: Ecologies of Memory', in (ed.), Memory in Twenty-First Century: New Critical Perspectives from the Arts, Humanities, and Sciences (Basingstoke and New York: Palgrave Macmillan, 2016), p.150.

8 Susannah Radstone, 'Reconceiving Binaries: The Limits of Memory'. History Workshop Journal, 59 (2005), pp.137. 
The idea of speculation is also pertinent to the difficulties of predicting exactly what the Anthropocene will look like. For example, the very idea of an anthropogenic, catastrophic environmental event its event-ness - needs to be rethought, given the ways such events unfold unevenly across time and space, their slowly violent effects often dislocated temporally and spatially from their causes. Dislocation is particularly complicated in the example of climate change, the effects of which turn into causes of further climatic transformation, or feedback loops, and with atmospheric thresholds crossed and tipping points met those transformations can be dramatic, sudden, not necessarily predictable, and anything but gradual. More generally, in the, as Rob Nixon would put it, 'slow' as well as fast violence of environmental catastrophe, human activity sets in motion a chain of action - the environment itself is lent a catastrophic agency - that exceeds human control. ${ }^{9}$ As Jane Bennett might put it, this is 'the capacity of things [. . .] to act as quasi agents or forces with trajectories, propensities, or tendencies of their own', which means that the 'locus of agency is always a human-nonhuman working group', an ad hoc 'assemblage'. ${ }^{10}$ The emphasis on Anthropocenic futures as speculation, and from those possible futures the back casting of their aetiologies through the work of speculative memory, also mitigates somewhat the teleological desire to read ourselves from the future whilst maintaining the idea of scientifically possible and probable if not prescribed scenario.

This essay will ultimately turn to the genre fiction of Paulo Bacigalupi, particularly his recent novel The Water Knife (2015), as an

\footnotetext{
9 Rob Nixon, Slow Violence and the Environmentalism of the Poor (Cambridge: Harvard UP, 2011).

10 Jane Bennett, Vibrant Matter: A Political Ecology of Things (Durham, NC.: Duke UP, 2010), pp.viii, xviii,
} 
example of a speculative-memory text. ${ }^{11}$ The Water Knife is a hybrid of science- and detective fiction set in a near-future climate-changed world of the American Southwest, and, more particularly, Arizona. This is the latest instalment of what could be described as Bacigalupi's dramatization of the effects of the Anthropocene as it unfolds in near- and not-so-near futures of broad-spectrum ecological collapse, meteorological and hydrospheric instability, resource scarcity, and alternative (but often fragile) energy systems. ${ }^{12}$ The precarious resource in question in The Water Knife is not oil - as it usually is in climate-change fictions of the future - but water, and the effects of climate change are felt not through hurricane and flood often typical icons mobilised by climate-change fiction - but through drought, dust storms and desertification. More accurately described as a form of speculative memory more than speculative realism, Bacigalupi's The Water Knife thematises mediation and so draws attention to its own work as a (sub)genre. Doing so, it raises a series of questions about the genre of the novel more generally, and its speculative subgenre, in the face of the Anthropocene and whether genre and subgenre are capacious enough to represent the geological. A triangulation of the work of, in particular, Wai Chi Dimock Mark $_{2 x}$ McGurl and Timothy Clark on issues of planetary scale and literary mode will provide the theoretical framework for answering these questions.

The Water Knife is set in a near-future Arizona in climatechanged, drought- and dust-storm-ridden American Southwest, when the idea of nation has undergone dramatic reconfiguration. Territorial sovereignty is now co-extensive with state borders, and the states themselves are effectively autonomous nations within a nation. While

11 Paulo Bacigalupi, The Water Knife (London: Little Brown/Orbit Books, 2015). Hereafter references will be made by page number above.

12 See for example, The Wind-Up Girl (2009), and collection of short stories Pump Six and Other Stories (2010), and young-adult novels, The Ship Breaker (2010) and The Drowned Cities (2012) 
a United States still exists, federal law, military and political authority rarely interfere with local government, and it seems that real political, economic and (para)military power lies with state water authorities which operate as capitalist corporations.

By controlling the flow of water into and across state sovereign territory, these corporations literally control the life and death therein. Exercising this biopolitical power, the water authorities can pool their resources in vast 'arcologies' - exclusive and gated commercial and residential communities for the wealthy, professional or wellconnected classes - built with Chinese corporate investment and technology and in which water is recycled through advanced bioengineered means. Or, water can be drained and cut off from cities and suburbs, turning residents into refugees, a deracination against which state or national citizenship affords little protection. Migration away from these biopolitical scenarios is impossible, at least legally, for all but the social, political and economic elite, as free movement across state borders is a thing of the past as the states attempt to conserve natural resources against the drain of an increased population. The novel's main setting of Phoenix, for example, is home to a huge influx of refugees from Texas after the collapse of that state's economy, natural resources and political and social infrastructures in the face of catastrophic climatic conditions - in effect an ecological collapse. The eponymous water knife and those like him are agents for the state water authorities, who take part in covert and overt intelligence gathering and paramilitary operations in order to protect the interests of their employers, which usually means helping to cut off the water supplies to cities and suburbs of other states. From this future the novel stages cultural memories of the Anthropocene, but before that literary remembrance is discussed, cultural memory studies needs to be recalibrated to the scales of the Anthropocene. With a recalibrated cultural memory studies in the place, the scalar capacities of the novel in general and the speculative- 
memory text in particular can be evaluated in terms of whether it can represent and activate remembrance of the Anthropocene.

The Enclosures of Culture and Criticism

The need for recalibration is exemplified in Tom Cohen's critique of the traditional bounds of memory studies, or 'mourning theory' as he terms it. ${ }^{13}$ Cohen finds that Judith Butler's work exemplifies the humanist grounding of the theory of cultural remembrance. In Butler's use of the future anterior, precarious life in zones of conflict and mass violence should be pre-mourned in advance as 'grievable' and so sustainable 'by that regard'. 'Grievable', life is recognised as potentially precarious, and, in the event of that precarity, recognised and remembered as life. ${ }^{14}$ In this sense, precarious life is reframed and recognised and apprehended as such. Butler's is a humanist frame, and for Cohen, no matter the ethics of framing life that will have been, such humanist grounds of remembrance, and humanist theories of memory, impede recognition of the imbrications of human and more-than-human worlds and so entrench human notions of absolute and transcendent human sovereignty over territory and the failure to think and see beyond the imagined boundaries of human exceptionalism. These 'political' and 'epistemological' 'homelands', as Cohen describes them, would demarcate the failure of memory studies to think ecologically, and therefore to remember ecological precarity and collapse. ${ }^{15}$

\footnotetext{
13 For a full discussion of the recalibration of cultural memory studies in the epoch of the Anthropocene, see Richard Crownshaw, 'Cultural Memory Studies in the Epoch of the Anthropocene', in Lucy Bond, Stef Craps, Pieter Vermeulen (eds), Memory Unbound: Tracing the Dynamics of Memory Studies (New York and Oxford: Berghahn Books, 2016), pp.242-257.

14 Judith Butler, Frames of War: When is Life Grievable? (London and New York: Verso, 2009), p.15.

15 Tom Cohen, 'Introduction: Murmurations - "Climate Change" and the Defacement of Theory', in Tom Cohen (ed.), Telemorphosis: Theory in the Era of Climate Change, Vol. 1 (Ann Arbour, University of Michigan Library: Open Humanities Press, 2012), p.15.
} 
The humanist reframing of life as grievable, and the idea of a posthumanist reframing of humanity's imbrication with the morethan-human, not only draws our attention to the conceptual difficulties of scaling up but also to the relation between the frame's scalar capacities and the mediations of the frame (its cultural forms, ideological underpinnings and historical specificities). These difficulties have driven the recent work of Tim Clark. In seminal fashion, and now rather famously, Clark called for a 'derangement' of the scales of literary theory and criticism in their confrontations with climate change. ${ }^{16}$ That call has become something of a mantra in literary critical writing about cultural representations of climate change, often becoming a substitute for an actual critical methodology. Or, to be fair, it leads to a number of similar conclusions drawn in literary criticism that point to the residual human plots, spaces and temporalities of the novel that are ironised by the scales of the Anthropocene, a sense of the epoch itself glimpsed only in its displacement.

Clark's most recent work on the Anthropocene and literary criticism registers some ambivalence towards the idea of derangement, or at least how it might be achieved in theory and cultural practice. That ambivalence is evident through a detailed reprisal of his thesis. As Clark has argued, the everyday practices by which we have habitually made sense of the world now have planetary implications, effecting a 'transpersonal agency' - agency that is mostly indiscernible at an individual level but more apparent at the collective level. ${ }^{17}$ The aetiologies of environmental degradation are complicated

16 Tim Clark, 'Derangements of Scale', in Tom Cohen (ed.), Telemorphosis: Theory in the Era of Climate Change, Vol. 1 (Ann Arbour, University of Michigan Library: Open Humanities Press, 2012), pp.147-67.

17 Timothy Clark, Ecocriticism on the Edge: The Anthropocene as a Threshold Concept (Bloomsbury, 2015), p.14. Hereafter referred to by page number above. 
by the combination and imbrication of the effects of everyday practices, magnified by the scale on which they are practiced, on emergent environmental conditions, which in turn intensifies those effects in feedback loops. Not only is it difficult to discern and isolate our individual agency, but also the conceptualisation of agency measurable and tangible at the collective level encourages abdication of moral and political responsibility and accountability at the individual level (p.72). That individual unaccountability, collectivised, leads to the magnification of inertia, the accumulation of our selfperceived insignificance as political and moral actors in scenarios of environmental destruction of our own making.

The normative cultural frameworks by which we apprehend the environmental compound the incalculability and unaccountability of our agency. The 'terrestriality' of these frameworks, as Clark describes it, is a 'prereflective sense of scale inherent to embodied human life on the Earth's surface [that] forms a kind of transcendental, one that both underlies and exceeds any view that it is merely our social context that determines our understanding of ourselves' (p.33). The scales of environmental cognition and representation are engendered by the immediacy of our localised senses of embodiment, when in fact embodiment produces a sense of the planet that is only 'epiphenomenal', 'delusory' for assumed scalar continuities between self and planet, and potentially 'ecophobic' in the disavowal and implicit denial of planetary processes and the ecological imbrication of human and more-than-human worlds all of which is culturally inscribed through a wholly inadequate, terrestrialising figurative language (pp.38, 33).

The compulsions of cultural terrestrialisation notwithstanding, the attempt to confront the Anthropocene through a scalar derangement brings about a set of cognitive problems or disorders of its own. Clark coins "Anthropocene disorder" to name a lack of 
proportionality, not out of a sense of old norms of consideration and demarcation calling to be restored, but of a loss of proportion tout court, vertiginously and as yet without any clear alternative' (p.23). The emergent scalar effects of the Anthropocene compound the disorder. For example, only now are the damaging and irreversible effects of modernity's (fossil-fuelled) progress becoming apparent, and the full extent of that damage is yet to be known if ever, as even retrospection cannot apprehend its emergent afterlife. In other words, the quotidian practices of modernity, exercised individually and collectively, are caught in a process of doubling, haunted by their cumulative effects to come (p.143). For Clark this doubling entails a new materialism in which materials not intrinsically toxic to life on the planet become transformative in new ways: carbon dioxide, for example, or the human body itself, which, when multiplied, drains resources, increases $\mathrm{CO}_{2}$ emissions through the quotidian practices of modernity, and so on, and so creates new forms of material agency (pp.58-9, 90, 103-4, 143). The conceptual leap needed to track let alone conceptualise the effects of scale from the local to the planetary does not so much lead to a cultural reframing of what had been terrestrialised but rather to a paralysing unframing of cognition and representation altogether.

For Clark a misplaced political faith in (traditional forms of) ecocriticism is a sign of that disorder, as if environmental destruction can be traced back to the way in which the environment is represented in literature and interpreted in criticism - as opposed to the "power of material modes of production, food habits, energy use, reproductive trends' (p.19-20) - and stemmed by the right kinds of representation and interpretation. Here the agency attributed the cultural imaginary - cultural production, dissemination, reception and critique compensates for culture's 'weakness as a sphere of agency' (pp.19-20), sustaining the delusion that 'endorsing certain symbolic or imaginary events may be far more crucial or decisive than it really is' and 
running the 'risk of consolidating a kind of diversionary side-show, blind to its relative insignificance' (pp.19-21).

In sum, then:

The Anthropocene names a newly recognized context that entails a chastening recognition of the limits of cultural representation as a force of change in human affairs, as compared to the numerous economic, meteorological, geographical and microbiological factors and population dynamics, as well as scale effects, such as the law of numbers, that arise from trying to think on a planetary scale. (p.21)

And this is where the tensions of Clark's work become apparent. While resistant to a simplistic model of literature as the 'superstructure' to its socio-environmental base, and in spite of the 'chastening recognition of the limits of cultural representation', there is clearly an investment in the role of literature (and art more generally) as a possible means of imagining the Anthropocene. So, and with those cautions about interpretational disorders notwithstanding, Clark advocates reading practices that do not simply recontextualise, illuminate and retrieve the implicit or immanent environmental content of past or present literatures and their relation to the Anthropocene. Retrieval would certainly render the intellectual enclosures' of literary practice and interpretation - for example, identifying the text's relations to national literary movements and historical contexts - inadequate frameworks in the face of the Anthropocene's deeper and vaster temporal and spatial coordinates (pp.52-4). However, Clark advocates reading within multiple and contradictory frames or scales at the same time rather than substituting the planetary and geological for the local (pp.108, 131). After all, given the interpretive framework of the Anthropocene is itself emergent (its effects are unfolding) there are not the stable grounds 
for such an act of retrieval. Moreover, removed from its immediate contexts of production and reception, be it contemporary or not, literature makes little sense in relation to incomprehensible (scaled Rick Crownshaw 20/2/2017 13:08 up) or as yet unknown frameworks. So, Clark recommends synchronous and diachronous readings (pp.62-3) in which one scale does not supplant the other, and the disjunction and tension between the two 'becomes a measure of some intractable break in consciousness and understanding' (p.54). That said, Clark then goes on to find the novel not fit for purpose in the face of the Anthropocene, which leaves scalar recalibrations a matter of literary theory rather than actually practiced by the novel, even though, as he admitted, the novel's significance may be found in the disjunction of its scale frames and those of the geological.

In Clark's about-turn the novel cannot free itself from its habitual purview of human drama even when humanity has attained a collective, thing-like force and when that force reveals the imbrications of the human and more-than-human world (p.103); the novel's ability to generate empathy across cultural and social divisions does not easily extend to species boundaries or self-reflexive thinking as a species (pp.59, 182); narrative emplotment, symbolism and imagery cannot contain environmental events, such as 'tipping points, which are not unitary by nature but the 'contingent emergent sum of innumerable and probably incalculable processes happening across the Earth at divergent time scales' (p.80); literary strategies are generally designed to provoke an emotional interest in human drama but which are 'at odds with the scale, complexity and multiple and nonhuman contexts involved' in the Anthropocene (p.181); and such dislocated events do not lend themselves easily as focal points for the dramatization of human community (p.198); finally, environmental destruction is often the subject of genre fiction, such as science fiction, of which the pleasure of reading detracts from the potential pedagogical and political efficacy of the novel (p.189-90). All of these 
are of course fair criticisms of the novel, but to be ungenerous for a moment, perhaps Clark's ambivalence towards the novel, and the consequent ambiguity of his argument suggests a kind of Anthropocene disorder of his own. However, read productively this disorder provokes further investigation of the problem of scale.

\section{A Dialectics of Expansion and Contraction}

Mark McGurl places, it seems, more faith in the disjunction of literary and geological scales. McGurl's conception of 'cultural geology' ironises the 'residual humanism' of the evolution of literary modes of perception and reception and their claims to new and ever-more selfreflexive forms of representation and extensive purviews. Successive literary movements are haunted by the geological time that precedes and will succeed humanity's social institutions and processes and cultural practices, and by the afterlife of human agency as it engenders transformations of the planet's chemistry that are geologically inscribed as a future record. These are 'glimpses [of temporalities and spatialities] we hallucinate, in various cultural works, of the unincorporated remainder of the work of all periods and schools' that simultaneously ground and unground cultural production in their anteriority and otherness. ${ }^{18}$ McGurl's cultural geology describes a latent significance in the operations of culture, and literature more specifically, rather than culture's meaninglessness within the emergent framework of the Anthropocene.

McGurl's terrestrialisation of the Anthropocene is prompted in part by a response to Wai Chee Dimock's conceptualisation of the 'deep time' of national literature. At the heart of Dimock's enquiry is the attempt to unground the idea of nation, and particularly 'America', as a parochial, organising principle of literary studies. Radically

18 Mark McGurl, 'The New Cultural Geology', Twentieth-Century Literature, 57.3-57.4 (2011), p.381. 
developing postnational and transnational literary studies, Dimock questions the assumptions behind Americanist literary studies in which the assumptions subtending the literary critical adjective 'national' engenders 'a mode of literary causality' that makes 'the nation' the cause of literary production and literature simply a reflection of 'the nation' and so co-extensive with national boundaries. ${ }^{19}$ This 'seemless correspondence' between the perceived time and space of the (one) nation is reproduced in literary creative and critical practice: the 'borders of knowledge' simply replicate national borders and vice versa (p.3). In reality, Dimock, argues, "American"' is a 'shorthand' for a

criss-crossing set of pathways, open-ended and ever-multiplying, weaving in and out of other geographies, other languages and cultures. These are input channels, kinship networks, routes of transit, and forms of attachment - connective tissues binding America to the rest of the world. Active on both ends, they thread American texts into the topical events of other cultures, while also threading the long durations of those cultures into the short chronology of the United States. This double threading thickens time, lengthens it, shadowing in its midst the abiding traces of the planet's multitudinous life. (p.3)

The reality of the 'deep', 'thick' time of the nation de-centres American culture and society as it circulates in the world, recognising the world's social and cultural circulation in America. The 'interactive' social and cultural fabric of America binds the nation to the 'projective' and 'recessional' times of elsewhere, and this binding of millennia and continents to America deregulates 'American' time and space, 'extending' it for 'thousands of miles' and 'thousands' of years.

19 Wai Chee Dimock, Through Other Continents: American Literature Across Deep Time (Princeton and Oxford: Princeton University Press, 2009), pp.2-3. Hereafter by page number above. 
Deregulated, the monumentalised time of America, from its colonial and republican origins to the present day, cannot contain, homogenise and naturalise the heterogeneous 'fabric' that is America (p.4).

'Deep time' therefore constitutes a postnationalist form of historical thinking that produces analyses and narratives of the long duree, the different data, archives and 'analytic fabric' of which throws into 'relief trajectories and connections' otherwise obscured by the standardised metrics of nationalism (pp.4-5). Illuminated are the long spatially interwoven histories of the formation of languages, religions, cultural and literary forms, and indeed the social, cultural and political practices of our species, which, even if unchronicled when unfolding, are imprinted onto later expressive forms. In thinking about the deep, planetary time of the relation between the human species and literature, Dimock does not privilege modern literature and the modern literary critic with the planetary consciousness benefitting from a very extensive hindsight - but rather finds a complex intertextual, non-linear evolution of that kind of thinking in literature across deep time. Ultimately, in thinking planetarily and searching for thinking about the planet, the scales of Dimock's enquiry are geological and astronomical (pp.5-6).

This is not just the literary imprint of the progression of the species but of humanity's imbrication with the more-than-human. ${ }^{20}$ In other words, the idea of the nation (and national narrative) is always belied by the ecological. As Dimock argues elsewhere, this was particularly apparent in the context of Hurricane Katrina. The idea of

20 As Lawrence Buell states, quoting Joseph Nye, "the oldest form of globalisation is environmental", given the planetary scale of environmental processes, before the expansion of the political or economic. Lawrence Buell, "Ecoglobalist Affects: The Emergence of U.S. Environmental Imagination on a Planetary Scale', in Wai Chee Dimock and Lawrence Buell (eds), Shades of the Planet: American Literature as World Literature (Oxford and Princeton: Princeton University Press, 2007), p.227. 
territorial sovereignty did not protect the racialised poor of New

Orleans and the other storm-affected areas of the Gulf coast. A

national narrative of the redemption of slavery through

enfranchisement, participation in the capitalist economy and Civil

Rights was exposed as fantasy as the floodwaters receded and the disposability of the living and the dead became visible. Put otherwise the nationalist container of American history was breached by the floodwaters, human disposability evidencing a deep-routed counterhistory of continuing structural racism. ${ }^{21}$ This breach of a national history was not just regional but planetary. The warming of the ocean surfaces brought about by climate change facilitates the frequency and intensity with which hurricanes are generated. ${ }^{22}$ The disposable lives of the inhabitants of the Gulf Coast manifest the intersection of Anthropocene histories (particularly of Anthropogenic climate change) and histories of structural racism (most evident in the American South). If the levees of national(ist) history have been breached, flooded by a history of the machinations of disposability and a social history of Hurricane Katrina, those histories are not just local in origin but are borne by 'cross currents affecting the entire planet, a seascape turbulent and borderless' histories that are 'oceanic rather than territorial'-for hurricanes interconnect the planetary phenomena of climate change and the local regime and instantiation of disposable life. Hurricanes are 'indexes to the hydrology of the world as whole', and this 'single, crisscrossing, and already-damaged hydrology makes it clear that climate, geology, and human and nonhuman life are all complexly intertwined, part of the same fluid continuum'.23

21 Wai Chee Dimock, 'World History according to Katrina', in Russ Castronovo and Sandra Gillman (eds), States of Emergency: The Object of American Studies, (Chapel Hill: University of North Carolina Press, 2009), p.144, 152 .

22 Dimock, 'World History according to Katrina', pp.150-2.

23 Dimock, 'World History according to Katrina', pp.150-152, 156; see also

Ross Gelbspan, 'Nature Fights Back' in The South End Press Collective (ed), 
The problem here is how to keep in sight 'the familiar', as Robert Levine puts it, alongside the planetary in the articulation of catastrophe. ${ }^{24}$ To what extent does a dispersed planetary history of climate change subsume differentiated, nuanced and localised let alone national histories of neglect and oppression? [This is the very problem that Clark struggles with (in a disorderly fashion): the tense co-presence of localised significance and the vertiginous scales of the Anthropocene.] Indeed, this is in essence McGurl's concern - that localised historical representation or textual historicity fails because dislocated by matters of scale. His consequent critique of Dimock progresses our conceptualisation of literature in the Anthropocene. The intertextual imprint of deep time and vast space on literature is contingent on the historically specific conditions and intentions of that literature's production (and indeed reception), particularly when that literature is nationalist in orientation - conditions which are too easily overridden by the deepening of literary time, argues McGurl. ${ }^{25}$ This is a symbolic escape into 'frictionless' transnational sympathy and identification, at the expense of that literature's political and economic implications, ${ }^{26}$ implying instead a universal humanism that binds all literature. Equally troubling for McGurl is the fact that in the attempt to undo the idea of American exceptionalism - an ideologically driven fantasy that has rationalised imperialist thought and praxis Dimock has reinscribed the logic of imperialism by staging American

What Lies Beneath: Katrina, Race and the State of the Nation, (Cambridge, MA: South End Press, 2007), pp.15-27.

${ }^{24}$ Robert S. Levine, 'American Studies in an Age of Extinction', in Russ Castronovo and Sandra Gillman (eds), States of Emergency: The Object of American Studies (Chapel Hill: University of North Carolina Press, 2009),pp.177-79.

25 On this, see also the continuing debate between McGurl and Dimock in Mark McGurl, 'Critical Response II: "Neither Indeed Could I Forebear Smiling at My Self”: A Reply to Wai Chee Dimock', Critical Inquiry, 39 (2013), pp. 632-38.

${ }^{26}$ Mark McGurl, 'The Posthuman Comedy', Critical Inquiry, 38.3 (2012), pp.533-34. 
literature as a (dehistoricised) departure point for other times and spaces, literatures and nations.

McGurl's critique is perhaps based on the principles of Dimock's project rather than some of its careful, historicist readings of American literature, but what it highlights is a shared concern for apprehending geological scale. While McGurl champions the extension of 'potential empirical observation, from the subatomic to the cosmic realms', the cultural relevance of this expansiveness can only be sought through a 'dialectical negotiation' of the 'natural-historical' and 'political-economic', of 'expansion and contraction', and that 'principle of limitation' will 'give that vaulting largeness and longness a meaningful form. ${ }^{27}$ For McGurl, one possible form is genre fiction (specifically science fiction and horror), which may not predate the nation state, and may postdate it, This is the 'posthuman comedy' of genre fictions, which, in their 'primordial flexibility', are 'willing to risk artistic ludicrousness in their representation of the inhumanely large and long', fictions that are inhuman or posthuman in their attempt to 'cross the threshold of the human', imagine other species and/or the demise of our own, and collapsing human, exceptionalist identity into mere matter. ${ }^{28}$ For all his concern with Dimock's methodology, McGurl's posthuman sense (of genre) humour corresponds with the genre she privileges as capacious enough to bear the scalar imprints of the Anthropocene - and not only that but a genre she describes in the context of cultural memory.

For while McGurl argues for a dialectics of expansion and contraction, Dimock 'points to a dialectic of negotiability and nonnegotiability', which keeps 'alive' the 'relative autonomy' of literature as a 'phenomenal register' of the Anthropocene. If the geological cannot contain literature and literature is uncontained by

27 Mark McGurl, 'The Posthuman Comedy', p.540.

28 Mark McGurl, 'The Posthuman Comedy', pp.539, 550-51. 
literature, then there will always be a cultural residue of relevance and an excessive geological or astronomical unassimilable remainder. ${ }^{29}$ Dimock's version of cultural geology, or dialectical form, arises from a consideration of the memorative capacity of genre, which is informed by an aspect of evolutionary psychology that compels humanity to continue representing - an attempted cultural containment of the alien temporal and spatial magnitudes of planetary history in which the species finds itself. This culturalization of the planetary is a way of 'telescoping in reverse, turning unthinkable orders of magnitude into thinkable ones'. ${ }^{30}$ The conceptualisation if not the realisation of the deep history of media would imagine a record of humanity's attempts to remember itself in this vastness, and literary genre's 'actualized embodiment' of the historically and materially specific inscriptional, representational and transmissional vehicles by which words are channelled into the world'. The attention to this 'symbiotic' relation between media and genre yields a 'scalevariable field, micro in is local articulations and macro in its causal coordinates' 31 , as words are transplanted from media to media and text to text. In other words, this is the intertextual imprint of the planetary on literature deeply temporalized. Dimock identifies epic as a particularly durable genre for its reinscription and recitation of the human species' fear of impermanence and insignificance. The genre therefore operates as a form of cultural memory across some (but certainly not all) of humanity's longue durée, as themes, plots and just clusters of words are remembered across time in their phrasing of these immemorial, species-fears. ${ }^{32}$ Dimock finds in the novelistic genre of science fiction in particular the 'downsizing' of the epical - a form of 'low epic' -and so a continuation of the 'microcization' of the macrocosmic. ${ }^{33}$

29 Dimock, 'Critical Response I: Low Epic', Critical Inquiry, 39 (2012), p.615.

30 Dimock, 'Critical Response I: Low Epic', p.619.

31 Dimock, 'Critical Response I: Low Epic', pp.622-3.

32 Dimock, 'Critical Response I: Low Epic', p.627.

33 Dimock, 'Critical Response I: Low Epic', pp. 623, 629, 631. 
This exploration of scalarity illuminates the limits and possibilities of literature in the Anthropocene. While Clark's disorderly ambivalence about the novel form sets out literature's limitations (and a way of productively reading them), a dialectics of McGurl's and Dimock's theories has identified the possibilities of genre fiction, particularly science fiction, in terms of its scalar capaciousness - and here both critics ultimately seem to share a sense of (posthuman) humour - a dialectics to which Dimock adds the memorative orientation of genre. More particularly, the incessant focus on genre in this literary-critical history foregrounds genre's materialisation of the historical specificity of the cultural mediations of the Anthropocene and its remembrance.

Paulo Bacigalupi's The Water Knife

\section{Positioning the literature of speculative memory as a}

development of the medial and memorative implications and potential of low epic and posthuman comedy, this essay now explores the genre fiction of Bacigalupi's The Water Knife. The plot of The Water Knife centres around three protagonists and their focalised narratives: Angel Velasquez, recruited out of a Mexican jail by the Southern Nevada Water Authority but now a veteran undercover operative on a mission in Phoenix; Maria Villarosa, her family originally from Mexico, a Texan refugee peddling water, when she can buy it cheaply, and, sometimes, her own body in order to survive; and Lucy Monroe an out-of-state investigative journalist drawn to a Phoenix on the verge of ecological collapse for its raw journalistic material but who stays out of empathy for its population. The plot is convoluted, although the story is relatively simple: the paths of all three protagonist's converge as they witness or investigate a series of murders of hydrologists and 'water lawyers', amongst others, who have played a part in the
Rick Crownshaw 20/2/2017 13:31

Deleted: the

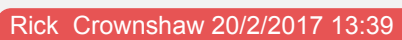

Deleted: With the scalar and memorative

Rick Crownshaw 20/2/2017 13:41

Deleted: , also known as Rick Crownshaw 20/2/2017 13:37

Deleted: or the literature of speculative memory, in mind, 
attempted theft and sale of 'senior' water rights sought after by the rival water authorities of California, Arizona and Nevada. (Water rights to rivers, their tributaries and mountainous sources are a source of interstate political strife and litigation, prompting paramilitary actions to cut off and defend the flow of water across territory). These senior rights to water from the Colorado River, date back to the late nineteenth century, and, at the time the river was thought to be dying, were sold by the Pima tribe to the State of Arizona (p.230). The rights were originally obtained by the Pima as part of a reparations deal, presumably for the ethnic cleansing and territorial expropriation of tribal lands - although the novel does not elaborate on this. In the present-day US, as it is in Bacigalupi's future, the Central Arizona Project (CAP) is a canal fed by water from Lake Havasu, itself fed by the Colorado River. The CAP brings water across the desert to supply Arizona, but was obviously not in existence when the Pima tribe sold their rights to the Colorado River. Those rights, and related territorial and water agreements, having been excavated from the archives of The Bureau of Land Management, Bureau of Indian Affairs and the US Army Corps of Engineers, now not only secure Arizona's water supply via the CAP but also water supplies to California and Nevada drawn from the Colorado River (p.231). Whatever the health of the Colorado River, senior rights to it means power over all three states and their environments: irrigation, hydroelectric generation and drinking water. Worth killing for, the pursuit of these rights drives the plot.

Not only a plot device, these archived documents reference a history of ethnic cleansing and genocide that prefaces the territorial violence committed over the natural resources of the novel's present setting. In fact, that violence is broadly continuous with the ecological nature of nineteenth-century imperialism and colonialism (in which the annexation and settlement of lands fundamentally affected prevailing ecosystems and environmental conditions). In turn, the so- 
called settlement of the West is rooted in the colonisation of the Eastern seaboard in the seventeenth century, which Simon Lewis and Mark Maslin have recently argued as a possible inception date for the Anthropocene, given the reduction in $\mathrm{CO}_{2}$ levels brought about the decimation of indigenous peoples, alongside the irreversible reordering of the American biosphere through the transatlantic importation of fauna, flora and agricultural systems. ${ }^{34}$ This long ecological history of settlement is not so much narrativised by the novel but subject to the protagonists' cultural memory: Angel 'could imagine Civil War-era military guys, sitting across the table from the Indians they had destroyed, scratching out agreements on parchment sheets. Each man handing a feather quill to the next, dipping the sharp tip in ink, each man scratching his name on paper' (pp. 334-5). This, then, is memory work from a speculative future of an unfolding Anthropocene, which although emplotted in a generic formula - and, often, so recognisably focalised with the characteristic nonchalance of a generic anti-hero - is potentially capacious in its ecology of settlement.

The generic convolutions of plot affords the diegetic space and time for such memory work, also allowing the narrative to unfold the quotidian, embodied experience of living through the drought and dust storms of a climate-changed American Southwest: the unwashed bodies and clothes encrusted with dirt; the thirst; the cough from pneumoconiosis; the necessity of drinking recycled urine with its ammonia reek; the potential exposure to airborne fungal diseases thriving in this climate; reliance on public water pumps, installed by the Red Cross but from which water has to be purchased at a variable market price, rather than on a domestically tapped supply (e.g., pp.72-3, 66); and therefore the embodied experience of the biopolitical regime that governs life under such conditions. (It is worth noting that catastrophic climate change is not delimited to one region:

34 Simon L Lewis and Mark a Maslin, 'Defining the Anthropocene', Nature, 519 (2015), pp.171-80. 
desertification and drought may be a Southwestern phenomena but

the Northeast is subject to floods and hurricanes that have, it seems,

already claimed the Gulf and Caribbean Coasts. As Lucy muses,

'Nothing lasts forever, so why should she try to fight her own end?

Phoenix would fall as surely as New Orleans and Miami had done.

Just as Houston and San Antonio and Austin had fallen. Just as the

Jersey shore had gone under for the last time' (p.70).) Bringing an

outsider's critical perspective in their respective ways, the three

protagonists' experiences are differentiated according to their socio-

economic standing, but the experience of heat, dust, dirt and thirst is always foregrounded in this literary phenomenology.

Contrary to Clark's anxieties over localised, embodied apprehensions of the Anthropocene, and actually correspondent with a more capacious framing of precarious lives, the phenomenological micro-register of the epoch in Bacigalupi's novel, the body, speaks volumes about climate change, or, to be more precise, materialises ecological memory. The novel opens with sentiments about the body that are implicitly focalised from Angel's perspective:

There were stories in sweat.

The sweat of a woman bent double in an onion field, working fourteen hours under the hot sun, was different from the sweat of a man as he approached a checkpoint in Mexico, praying to La Santa Muerte that the federales weren't on the payroll of the enemies he was fleeing. The sweat of a ten-year-old boy staring into the barrel of a SIG Sauer was different from the sweat of a women struggling across the desert and praying to the Virgin that a water cache was going to turn out to be exactly where her coyote map told her it would be.

Sweat was a body's history, compressed into jewels, beaded on the brow, staining shirts with salt. It told you 
everything about how a person had ended up in the right place at the wrong time, and whether they would survive another day. (p.1)

Localised bodies in all their precarity give way to a commentary on the progression (or regression) of the human species. At the beginning of the novel, Monroe wakes from an affective dream of rain, which turns into a commentary upon the irony of the idea of Manifest Destiny, given the ecological realities of the twenty-first century to which she has awoken.

The dream had seemed so real: the rain pouring down; softness in the air; the smell of plants blossoming. Her clenched pores and the tight clays of the desert all opening wide, welcoming the gift - the land and her body, absorbing the miracle of water that fell from the sky. Godwater, American settlers had once called it as they invaded slowly across the prairies of the Midwest and then pressed into the arid lands beyond the Rocky Mountains.

Godwater

Water that fell of its own volition, right out of the sky. (p.19)

This cultural memory of Manifest Destiny also recalls the fact that the geophysical agency of humanity now affects whether the rain falls, or not as the case now seems to be. The idea of Manifest Destiny remains a present absence in the text as a means of assessing the reality and tenability of this national narrative. Not only is territorial sovereignty confined to state rather than national borders, but also the image of migration no longer serves the idea of the nation's progress across the continent. For example, the novel ends against the backdrop of the collapse of Carver City, following the cutting of the water supply to its reservoir by the water knifes of the Southern Nevada Water Authority Rick Crownshaw 20/2/2017 14:15 Deleted: al Rick Crownshaw 20/2/2017 14:15 Deleted: ... [1] - an action in which Angel was involved at the beginning of the novel. 
The drought means there is no other water supply, turning the city's residents into climate-change refugees and their evacuation the march of American regress and rather than progress. Not just the inversion of Manifest Destiny, this backdrop inspires an archaeological | imaginary in all three protagonists. Looking back at Phoenix, Angel and Lucy wonder whether the city will become the 'next Hohokam civilization' (p.345; see also p.98), a lost and buried civilization to be excavated in the future: 'The Outdoors Period', 'Maybe that's what the archaeologists will call us', 'For when people still lived outdoors' (p.347), prior to seeking subterranean refuge against the climate. The historical irony is that the settler society will share the same demise as those displaced by Manifest Destiny.

Indeed that idea of future excavation of a possibly extinct species peppers Lucy's thoughts on her investigation of the body politic (p.18). Initially in Phoenix to peddle 'collapse pornography' for the media networks 'happy to feed on the corpse' of the city, its vulnerable inhabitants and of the deracinated of the Southwest generally, Monroe empathised with those around her and her journalism became more investigative and political:

Her critics said she was just another collapse pornographer, and on her bad days she agreed: just another journo hunting for salacious imagery, like the vultures who descended on Houston after a Cat 6 [hurricane], or the sensationalised imagery of a fallen Detroit being swallowed by nature. But on other days Lucy had the feeling that she wasn't so much erotizing the city's death as excavating a future as it yawned below them. As if she was saying, This is us. This is how we all end. There's only one door out, and we all use it. (p.24),

Rick Crownshaw 20/2/2017 14:16

Deleted: For example

Rick Crownshaw 20/2/2017 14:16

Deleted: , 1 
If Lucy is excavating the future of an extinct species, this is not an individual speculative future memory, but, as she muses, very much a regional cultural memory articulated in popular discourse: “The Hohokam are right underneath us. We're walking on their graves. They ran out of water, too! Look at them now. Gone. You know what Hohokam means 'All used up.' In other hundred years people won't even remember us. Won't even remember what Phoenix was"' (p.98).

While the body materialises, provokes and represents cultural memories, Bacigalupi constantly reminds us of the body's mediations, not least by the form and genre of the science fiction novel itself. The investigation of murdered bodies are obvious narrative devices to propel the plot towards the discovery or exhumation of a missing body of historical knowledge concerning the territorial politics and the capitalism of water in a climate-changed world and a wider ecological history of the Southwest. In turn, the unfolding of plot stages precarious bodies as affective registers of the Anthropocene that compel their historicisation - a historicisation confined to the expressive potential of genre fiction. Just as we are reminded of the genre of this fiction through its emplotment of bodies, bodies in the diegesis are subject to constant mediation and remediation. The digital media world of Monroe's journalism is referenced in the novel through, for example, the reproduction of hashtags, such as \#PhoenixDowntheTubes, and therefore a media ecology without which we cannot see precarity and environmental collapse. By way of another example, for Angel the omnipresence of digital media becomes apparent through its temporary interruption by dust storms (p.84).

In an interview of 2016, Paulo Bacigalupi spoke of the distractedness and limited temporal horizons induced by such immersive use of digital media culture and its mobile devices, and the way such cognitive delimitations screen the apprehension of radical 
environmental change over time. ${ }^{35}$ Put another way, the inhabitants of Bacigalupi's world may live with climate change, but they are literary and figuratively screened from its complex and extensive aetiologies and ecological dimensions (the relation between the human and nonhuman worlds). Ironically, these mobile media technologies are materialisations of the deep geological time - histories of the formation of minerals and metals, vital components of digital technologies ${ }^{36}$ and more recent social histories by which such materials are extracted, transported, processed, commodified, transported again, consumed, transported again, and disposed of (pp. 39, 41). Even then, this incessant deterritorialisation from geological origins does not stop (pp. 25, 28), as chemicals leach from e-waste and the eternal decomposition of difficult-to-soften hardware adds fossilised layers to the Earth's moving strata (pp. 39, 41). Not only could minerals and metals vital to digital technology not be accessed without extractive technologies brought into being (in their early stages) by the fossilfuel-demands of the industrial revolution, but the return of these minerals and metals to the Earth via obsolescence and pollution is further evidence of humanity's inscription of its geo-physical agency, and the fossilisation of technology is another addition to the geological archive, by which the Anthropocene is legible to future retrospection (pp. 29, 36-7). Bacigalupi's foregrounding of the ubiquity (if not the deep past and future history) of especially mobile, digital technology, which becomes the reader's (as much as the characters') interface with a climate-changed world, evokes for the reader a present absence and so an archaeological, interpretive framework.

Parikka is keen to address the geopolitical (intertwined corporate, governmental and military) knowledge systems enabled by

$35 \mathrm{http} / /$ / culturesofenergy.com/cultures-of-energy-podcast-1-paolobacigalupi/ 36 Jussi Parikka, The Anthrobscene (Minneapolis: University of Minnesota Press, 2014), pp. 3, 41, 44. Hereafter, references will be made by page number above. 
digital media (p.47), and so the political implications of the discipline of geology and it geological surveys of mineral resources, from its eighteenth-century origins to the present-day US geological survey (67), and, by extension, the future hydrology of Bacigalupi's world. In The Water Knife the digitisation of information serves both investigative journalism and corporate-sponsored paramilitary actions that cut off water resources to competing states. In an example of the latter, Angel sees the barren landscape of the Southwest through battle-software-enhanced lenses ('glass') that recognise, illuminate and profile targets, human and infrastructural. This digital rendering of the spectacularly visible effects of a biopolitically inflected Anthropocene may subsume a wider, ecological understanding.

The Anthropocene is further screened by the very media of digital culture itself. Parikka points out that the purported immateriality of digital culture, its infrastructures and its clouds of information, in the present and, presumably, Bacigalupi's future, is belied by the energy needed to power data servers and the consequent emission of $\mathrm{CO}_{2}$ (p.29). As Alison Carruth has argued, our reified representations of the internet stress carbon-neutral globalised communities networked together by ethereal, sublime infrastructures - a celebrated, socially transformative connectivity. ${ }^{37}$ What the cloud masks is 'an energy intensive and massive industrial infrastructure'; the 'coal-fired power plants and energy-intensive cooling systems that translate kinetic actions (all those keyboard strokes and touch-screen swipes into data)'; therefore, not just the energy and water needed to power and cool data centres, servers and farms but to power data processing through their internet-interface with global computing (which accounted for, according to Robert Marzec in 2011, 2\% of global $\mathrm{CO}_{2}$ emissions). ${ }^{38}$ As Carruth points out, carbon emissions are

Rick Crownshaw 20/2/2017 14:32 Deleted: $\mathrm{T}$ Rick Crownshaw 20/2/2017 14:32 Deleted: i Rick Crownshaw 20/2/2017 14:33 Deleted: in

37 Alison Carruth, 'The Digital Cloud and the Micropolitics of Energy', Public Culture 26, no. 273 (April 1, 2014), p.344

38 Carruth, pp.342, 346, 357. 
typically described as the footprint of a human activity, and, according to the $O E D$, 'footprint' is defined in relation to its fossilised form. ${ }^{39}$ It is of course the footprint of humanity's geophysical agency, inscribed in the Earth's strata, which evidences a new geological epoch. The digital media citizens of The Water Knife screen their own footprints or microcontributions to the climate that renders them biopolitically vulnerable.

In sum, Bacigalupi presents a media ecology that extends to the novel form itself, and its self-conscious subgenre, and becomes the means of cultural memory's inscription, reproduction and transmission. It is not incidental that the senior water rights integral to the novel's plot are found hidden in a first edition of Mark Reisner's Cadillac Desert (1986)..$^{40}$ A rare cultural artefact in Bacigalupi's world, if not in our own, this is a history of the attempts by The Bureau of Reclamation and the US Army Corps of Engineers from the nineteenth-century onwards to settle the West by geo-engineering the water supply of the region. As the hydrologist who once owned this copy (and hid the rights in it) said, before he was murdered: that was when 'we thought we could make deserts bloom, and the water would always be there for us. When we thought we could move rivers and control water instead of it controlling us' (p.179). In effect, this is a memory text within a memory text of the American Southwest.

The final pages of the novel ends with Maria in possession of the nineteenth-century documentation of the senior water rights, and she shoots Lucy to prevent the journalist from returning them to the authorities of Arizona. Maria would rather take up Angel's offer of safe passage for them (and the documents) to Nevada and the life of luxury and privilege in reward. The novel ends with the sound of SNWA

39 Carruth, p.356.

40 Marc Reisner, Cadillac Desert: The American West and its Disappearing Water (New York: Penguin Books, 1993). 
helicopters approaching, summoned by Velasquez, drowning out the sounds of the Colorado River on the banks of which they wait.

There is no guarantee of what will happen next, in terms of the immediate plot and, given the novel's Anthropocenic contextualisation of that plot, in terms of the human species. By absconding with the historical water rights, Maria leaves Arizona's population to a doubtful future, which we have seen presaged by the refugees of Carver City. Despite her own experiences as a refugee, she does not participate in a cultural memory that might find continuities between her own unhoming, that of Arizona's citizens, or of the Native American tribe that sold those rights in the first place, or indeed of the lost Hohokam civilisation. In many ways, this is a generic ending to be expected: a novelistic plot driven by individualistic human desire rather than an eco-historical consciousness, and perhaps that is precisely Bacigalupi's point, drawing us once again to the mediations of a memory text.

In terms of the work of genre, Rachel Adams might describe Bacigalupi's work as representative of or at least associated with a new wave of contemporary borderland crime/detective fiction. She focuses on fiction set on the US-Mexico border as an evolution of the genre that sees the borderlands as not so much an international or even transnational space but a localisation of the criminal effects of a globalised economy and thereby implicated in planetary consequences of late capitalism. ${ }^{41}$ As Adams points out, the genre has been highly exportable to other transnational borderlands, but Bacigalupi's setting is not too far from her focal point, even if his borderlands are between states as well as between the US and Mexico, and climate change for Bacigalupi is the planetary consequence of late capitalism, as well as

\footnotetext{
${ }^{41}$ Rachel Adams, 'At the Borders of American Crime Fiction', in Wai Chee Dimock and Lawrence Buell, eds, Shades of the Planet: American Literature as World Literature (Oxford and Princeton: Princeton University Press, 2007), pp.250-52.
} 
an opportunity for disaster capitalism's regulation and monetisation of the water supply.

As Adams notes, the genre registers 'disruptions in the social order, seeking imagined resolution to problems of morality, injustice, and the law that may be insurmountable outside of the domain of fiction'. ${ }^{42}$ Although Clark is cautious about the pedagogical and political efficacy of literature that addresses the Anthropocene - its under-researched effects - Adams finds in the popularity and malleability of the genre (its ability to relocate to other instances of global criminality) the potential constitution of critical communities or publics around these texts and the issues they address. The process of detection or investigation in Bacigalupi's novel does not seek resolution or social transformation but rather the narrativisation of the planetary, regionalised and embodied in the American Southwest. Indeed, Clark may be being too overcautious about separating textual politics from textual pleasure, as the latter may well constitute a reading public with affective ties to the subject matter as well as the genre itself.

Given the stubborn attachment to human plots and human territories dramatized by Bacigalupi, this example of genre fiction might be deemed to fail in what Colebrook has describe as proleptic mourning, succumbing instead to what she terms protomelancholia. The former is a recognition and memorialisation of past, present and future emergence, precarity and loss of species (human and (nonhuman) and ecosystems. Its political import lies in the potential address of, and legibility to, future generations, and what is left of the human species, if anything, as a cautionary tale and salutary lesson for living in a more fully evolved Anthropocenic or post-Anthropocenic world. The latter is the inevitable cultural reaction, a resurgent human exceptionalism, when we realise that ecological mourning

42 Adams, p. 250. 
implicates our own potential loss. ${ }^{43}$ It seems that the genre fiction of Bacigalupi has sought out a middle ground between mourning and melancholia, between reductive and expansive scales of cognition and representation, and therefore a culturally recognizable and significant middle ground that is often superseded by the ambitions of theories of the Anthropocene. While Clark registers an ambivalence towards the novel's restrictive residual humanism that risks opposing rather than simultaneously reading within multiple and contradictory frames or scales, the concept of speculative memory finds expressive potential in its medial and generic nature. Following Colebrook, it might in fact be more accurate to describe this kind of genre fiction as a form of postmelancholic speculation on the future, given its self-reflexive insistence on terrestrialising frameworks alongside its entertainment of ecological collapse and human extinction.

43 Claire Colebrook, Extinction (Open Humanities Press). Available at: http://livingbooksaboutlife.org/pdfs/bookarchive/Extinction.pdf. See also http:// thememorynetwork.net/the-anthropocene-and-thearchive/). 
